\title{
Behaviour of fibre reinforced concrete using steel slag coarse aggregate produced in Qatar
}

\author{
Wael Alnahhal ${ }^{1, *}$ \\ ${ }^{1}$ Assistant Professor, Department of Civil and Architectural Engineering, Qatar University, Qatar.
}

\begin{abstract}
The state of Qatar suffers from the shortage of natural resources needed for concrete production. Therefore, it is essential to investigate the feasibility of using by-product recycled materials as aggregates to maintain the concrete construction industry. Several types of recyclable materials are currently used in concrete. One of the potential resources of recycled concrete is steel slag. Knowing that Steel slag is the most significant solid waste generated by Qatar Steel Company in Qatar, replacing of natural coarse aggregate with steel slag aggregate will have a significant environmental and economic impact to the state of Qatar. This paper presents the compression and flexural test results of different concrete mixes made of steel slag coarse aggregate combined with a newly developed basalt chopped fibres. The parameters investigated included the volume fraction of the fibre used and the type of coarse aggregates (natural aggregates "Gabbro" and steel slag aggregates). Plain concrete specimens containing natural coarse aggregates and steel slag aggregates with no fibres added were also tested to serve as control. Test results showed that adding the basalt chopped fibres to the concrete mixes enhanced their flexural tensile strengths at different percentages. In addition, the compressive strength of concrete made with steel slag aggregate was higher than that made with natural gabbro aggregate. Test results clearly showed that steel slag aggregates can be used as sustainable and ecofriendly alternative materials in concrete structures.
\end{abstract}

\section{Introduction}

The State of Qatar has experienced tremendous economic development in the last decades. As a result, massive quantities of building materials have been used to accommodate the great pace in construction. The state is anticipated to spend USD 17 billion on its infrastructure as part of its preparation to host the Soccer World Cup in 2022. Most of these expenses will go towards the construction of new hotels, stadiums, facilities, and tourism's attractions (from Qatar 2022 bidding committee official website).

Concrete is the main material used in construction in Qatar and in most of the Gulf Cooperation Council (GCC) countries. However, most of these countries suffer from the shortage of natural resources required for concrete production. For example, the quantities

\footnotetext{
* Corresponding autour: wael.alnahhal@qu.edu.qa
} 
of imported aggregates in the State of Qatar have increased from 9.5 million tons in 2006 to 21.5 million tons in 2008 (data from the Qatar Customs Database). Therefore, it is essential to investigate the feasibility of using recycled materials in concrete production.

Several types of recyclable materials are currently used in concrete. One of the potential resources of recycled concrete is steel slag, knowing that steel slag is the most significant solid waste generated by Qatar Steel Company in Qatar [1]. Several researchers have shown that steel slag can be used as an aggregate in structural concrete [2-6]. The use of steel slag in concrete applications has major economic and environmental benefits to Qatar. Steel slag aggregate (SSA) can partially replace the relatively expensive imported Gabbro aggregates commonly used in Qatar, thus saving on the total cost of the concrete projects. Recycling the steel waste will also have a significant environmental impact due to the reduction in demand of virgin aggregates. Moreover, using waste materials would partially solve a significant environmental concern from land-filling the large quantities of waste materials produced every year in Qatar.

There has been always a general belief about the undesirable impact of using SSA in concrete production [2]. However, a number of publications have contradicted this idea [36]. Recently, a number of researchers studied the possibility of using steel slag in concrete mixes as a coarse aggregate to make sustainable concrete [3-4]. They reported that the use of the SSA improved the flexural and compressive strength of the concrete. According to a study by Krishnasami et al., it was reported that the flexural and compressive strength of self-compacted concrete made with coarse SSA is higher than that of the concrete with natural aggregate (NA) [5].

A number of studies focused on determining the optimal replacement percentage of coarse and fine aggregates by steel slag to produce a concrete that would accommodate a higher strength than the normal concrete. Devi et al. found that $40 \%$ and $30 \%$ individual replacement for fine and coarse aggregates by steel slag respectively resulted in improved compressive and flexural strengths [6]. In addition, Qasrawi found that the optimum percentage of slag aggregate replacement is $30 \%$ of coarse aggregate content [3]. Therefore, a proper mix design is necessary to obtain the required quality of concrete made of steel slag aggregate.

Previous investigations have shown that using discrete steel fibres in concrete increases its ductility due to the large compressive strains exhibited at failure [7-9]. However, among the disadvantages of using steel fibres is corrosion, especially in the harsh environment that characterizes the Arabian Gulf area, and the added weight to the concrete structure. Therefore, chopped basalt fibres were proposed in this study. Chopped basalt fibres are non-corrosive macro fibres made from basalt fibre-reinforced polymer bars. Chopped basalt fibres possess higher tensile strength and higher stiffness compared to conventional synthetic fibres [10]. The fibres act as a proactive reinforcement that provides the immediate tensile load carrying capacity when micro cracks develop in concrete. Bajaj [11] reported that the crack width that develops in plain concrete is larger than the crack width in polypropylene fibre concrete, which is larger than the crack width obtained in reinforced concrete having chopped basalt fibres in the mix.

This paper presents a part of a large research program that aims at investigating the feasibility of using SSA as a low-cost alternative sustainable material in fibre reinforced concrete (FRC). The program also aims at investigating the use of basalt chopped fibres in combination with SSA to produce sustainable concrete. The results of preliminary tests that have been conducted to determine the properties of the obtained FRC are presented. 


\section{Experimental program}

The aim of this experimental program is to characterize the properties of hardened FRC made of SSA in combination with chopped basalt fibres. The results of compressive and flexural tests are presented. Three different volume fractions of chopped basalt fibres were investigated. The properties of plain concrete containing $100 \%$ natural coarse aggregate with no fibres added to the mix were also tested to serve as benchmark for the FRC. The maximum aggregate size used in all concrete mixes in this study was $25 \mathrm{~mm}$.

\subsection{Materials and mixture proportions}

Type I Portland cement was used in this study. Washed sand was used as fine aggregate. The two types of coarse aggregate used were the Gabbro and the SSA. Gabbro is a natural coarse aggregate that is not available in Qatar but imported from the United Arab Emirates. On the other hand, the steel slag aggregates used in this study have been produced in Qatar as a by-product of steel manufacturing. Test results for the specific gravity and absorption ratio for both types of aggregates are shown in Table 1. As anticipated, the SSA showed higher specific gravity and unit weight and relatively higher absorption than the Gabbro aggregates. Figure 1 and Figure 2 show the sieve analysis obtained for both types of aggregates with respect to the upper and lower ASTM limits. It can be noticed that the SSA curve was close to the upper ASTM limit whereas that of the Gabbro aggregates was between the ASTM limits.

Six concrete mixes containing either natural or steel slag aggregates were studied and compared. The first mix was a control mix and did not contain any chopped basalt fibres. For other mixes, two volume fractions of chopped basalt fibres were used namely, $0.25 \%$ and $1 \%$. All mixes had a water/cement ratio of 0.51 . The weight proportions of all ingredients are shown in Table 2. The target compressive strength of all mixes was $40 \mathrm{MPa}$.

Table 1: Specific Gravity and Absorption Ratio for Gabbro and SSA.

\begin{tabular}{ccccc}
\hline $\begin{array}{c}\text { Aggregate } \\
\text { Type }\end{array}$ & $\begin{array}{c}\text { Bulk Specific } \\
\text { Gravity (Dry) }\end{array}$ & $\begin{array}{c}\text { Bulk Specific } \\
\text { Gravity (SSD*) }\end{array}$ & $\begin{array}{c}\text { Bulk Specific } \\
\text { Gravity (APP**) }\end{array}$ & $\begin{array}{c}\text { Absorption } \\
\text { (\%) }\end{array}$ \\
\hline Gabbro & 2.886 & 2.905 & 2.942 & 0.654 \\
SSA & 3.242 & 3.311 & 3.484 & 2.145 \\
\hline$*(\mathrm{SSD}=$ Saturated Surface Dry) & & & \\
$* *(\mathrm{APP}=$ Apparent) & & &
\end{tabular}

Table 2: Weight Proportions of the Ingredients.

\begin{tabular}{cc}
\hline Ingredients & Weight Proportion \\
\hline Cement & 1.00 \\
Water & 0.51 \\
Coarse Aggregate & 2.6 \\
Fine Aggregate & 2.5 \\
\hline
\end{tabular}




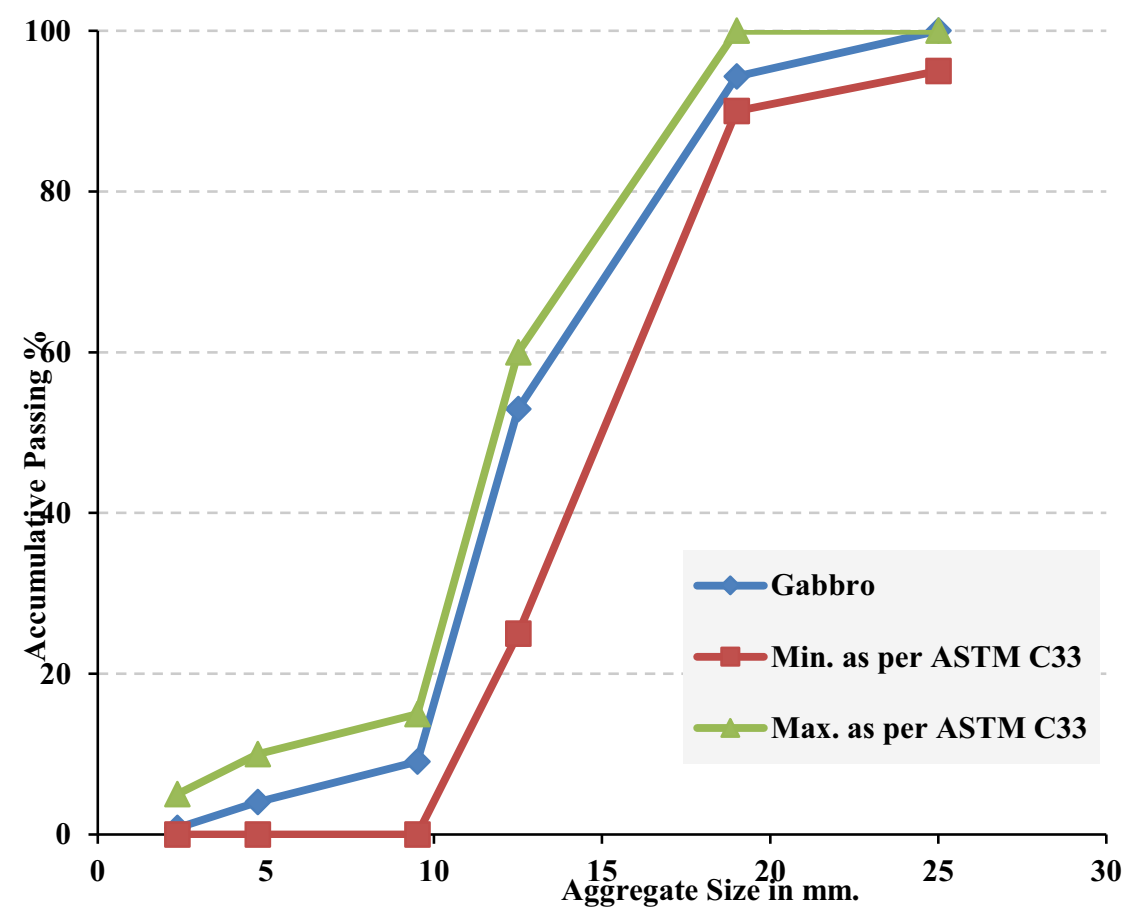

Fig. 1: Sieve Analysis for Gabbro.

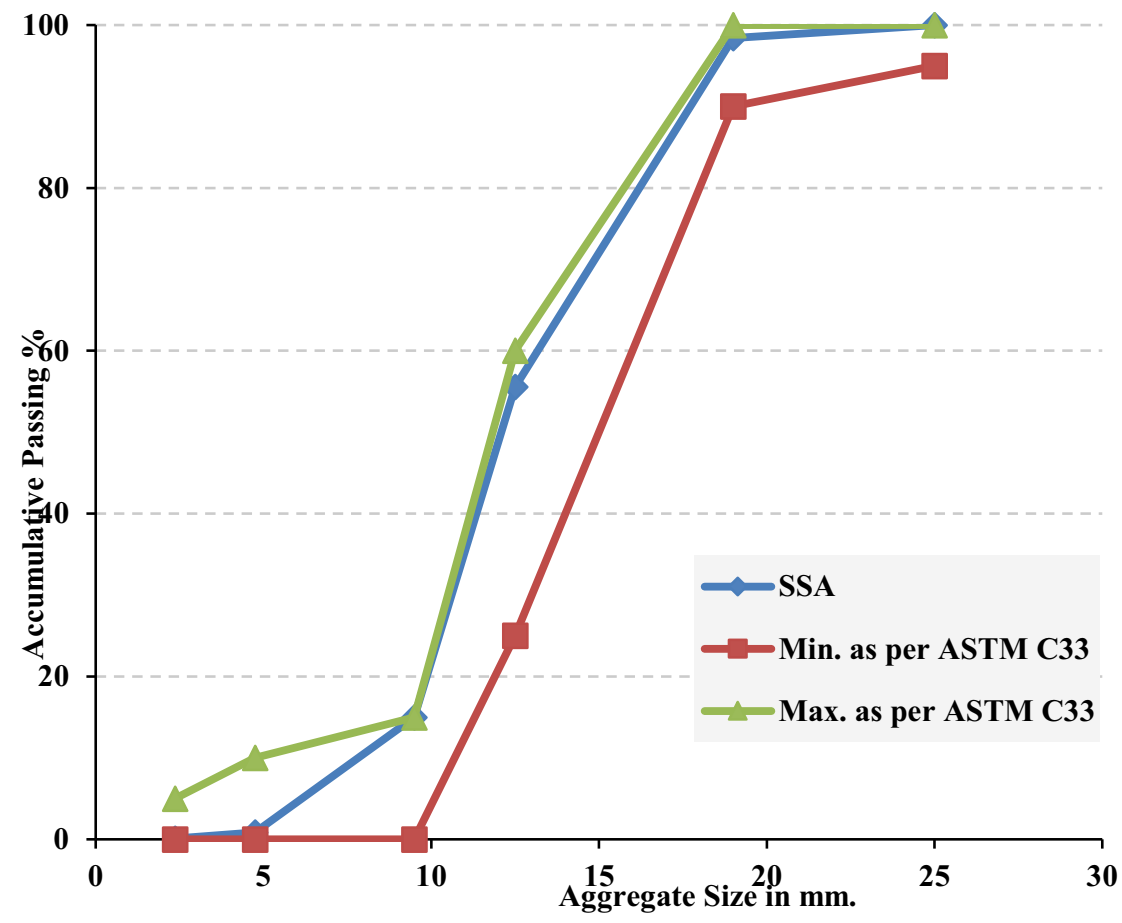

Fig. 2: Sieve Analysis for SSA. 


\subsection{Compression and flexural tests}

The compressive strength of all concrete mixes was measured using standard cylinders of 150x300 mm according to the provisions of ASTM C192/C192M-14. The cylinders were moist-cured for 28 days after mixing. Five test cylinders were performed for each mix after 28 days according to ASTM C39-14C. Three flexural strength tests were conducted for each mix using standard prisms of $150 \times 150 \times 500 \mathrm{~mm}$ according to ASTM C78-07. The aim of these tests was to study the effect of the fibres on the flexural performance of the hardened concrete. The prisms were tested under four-point loads until failure.

\section{Results and discussion}

The measured average compressive strengths are shown in Table 3. It was noticed that the average compressive strength of the concrete mixes made of Gabbro aggregate (G-1, G2, and G-3) were lower than that of the concrete mixes made of SSA (SSA-1, SSA-2, and SSA-3). As shown in Table 3, the compressive strength results indicated better performance of the fibre reinforced concrete over the control mix (without fibres) for steel slag aggregates. However, there is no correlation between the compressive strength and the percentage of fibre for gabbro aggregates, since increasing the percentage of fibre did not influence the concrete compressive strength.

Figure 3 showed the compression test results. It can be observed that adding a volume fraction of $0.25 \%$ to the Gabbro concrete resulted in an increase in the compressive strength of $17.4 \%$. However, the compressive strength increased by $15.4 \%$ when the volume fraction of the chopped fibres increased to $1 \%$. For concrete mixes with steel slag aggregates, adding volume fractions of $0.25 \%$ and $1 \%$ of the fibres to the mix resulted in an increase in the compressive strengths of $3.8 \%$ and $15.8 \%$, respectively. The increase in compressive strength in SSA mixes was obvious when fibres were added.

It is clearly observed that the compressive strength of concrete cast using SSA aggregate had better results than the concrete made with normal Gabbro aggregate. The average increase in the strength of SSA concrete was $15.2 \%$ compared with Gabbro concrete. This can be attributed to the high physical properties of the SSA compared to that of the Gabbro aggregates.

Table 3: Average Compressive Strength of Concrete Cylinders.

\begin{tabular}{cccc}
\hline Specimen & $\begin{array}{c}\text { Aggregate } \\
\text { Type }\end{array}$ & $\begin{array}{c}\text { Chopped Basalt Fiber } \\
\text { Dosage \% by Volume }\end{array}$ & $\begin{array}{c}\text { Average Compressive } \\
\text { Strength, } \boldsymbol{f}_{c}^{\prime} \text { (MPa) }\end{array}$ \\
\hline G-1 & Gabbro & $0 \%$ & 39.6 \\
G-2 & Gabbro & $0.25 \%$ & 46.5 \\
G-3 & Gabbro & $1 \%$ & 45.7 \\
SSA-1 & Steel Slag & $0 \%$ & 47.4 \\
SSA-2 & Steel Slag & $0.25 \%$ & 49.2 \\
SSA-3 & Steel Slag & $1 \%$ & 54.9 \\
\hline
\end{tabular}




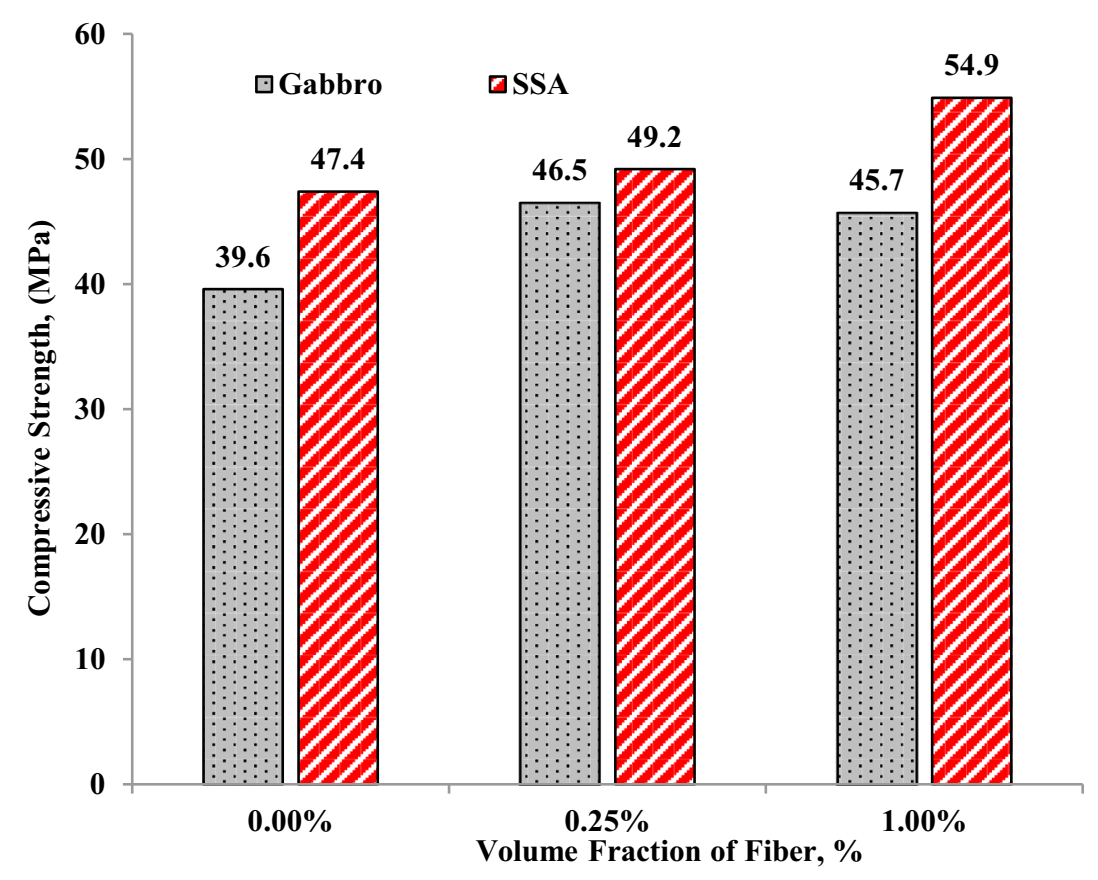

Fig. 3: Compression test results.

The measured average flexural strengths are shown in Table 4. There was an obvious better performance of the fibre reinforced concrete over the control mix (without fibres) for both types of aggregates used. Moreover, the effect of adding fibres to the concrete mix was more effective if compared to the compression test results. This is demonstrated in Figure 4 that compares the flexure test results of both types of concrete mixes. It can be observed that adding a volume fraction of $0.25 \%$ to the Gabbro concrete resulted in an increase of $9.6 \%$ in the flexural strength. The gain in flexural strength further increased to $23.3 \%$ when the volume fraction of the chopped fibres increased to $1 \%$. For concrete mixes with steel slag aggregates, adding fibres with volume fractions of $0.25 \%$ and $1 \%$ to the mix resulted in an increase in the flexural strength of $14.1 \%$ and $29.8 \%$, respectively.

It is clearly observed that the tensile strength of concrete cast using SSA aggregate had slightly better results than the concrete made with normal Gabbro aggregate. The average increase in the strength of SSA concrete was $6.7 \%$ compared with Gabbro concrete.

Table 3: Average Flexural Tensile Strength of Concrete Prisms.

\begin{tabular}{cccc}
\hline Specimen & $\begin{array}{c}\text { Aggregate } \\
\text { Type }\end{array}$ & $\begin{array}{c}\text { Chopped Basalt Fiber } \\
\text { Dosage \% by Volume }\end{array}$ & $\begin{array}{c}\text { Average Tensile } \\
\text { Strength, } \boldsymbol{f}_{\boldsymbol{r}} \text { (MPa) }\end{array}$ \\
\hline G-1 & Gabbro & $0 \%$ & 6.04 \\
G-2 & Gabbro & $0.25 \%$ & 6.62 \\
G-3 & Gabbro & $1 \%$ & 7.45 \\
SSA-1 & Steel Slag & $0 \%$ & 6.25 \\
SSA-1 & Steel Slag & $0.25 \%$ & 7.13 \\
SSA-1 & Steel Slag & $1 \%$ & 8.11 \\
\hline
\end{tabular}




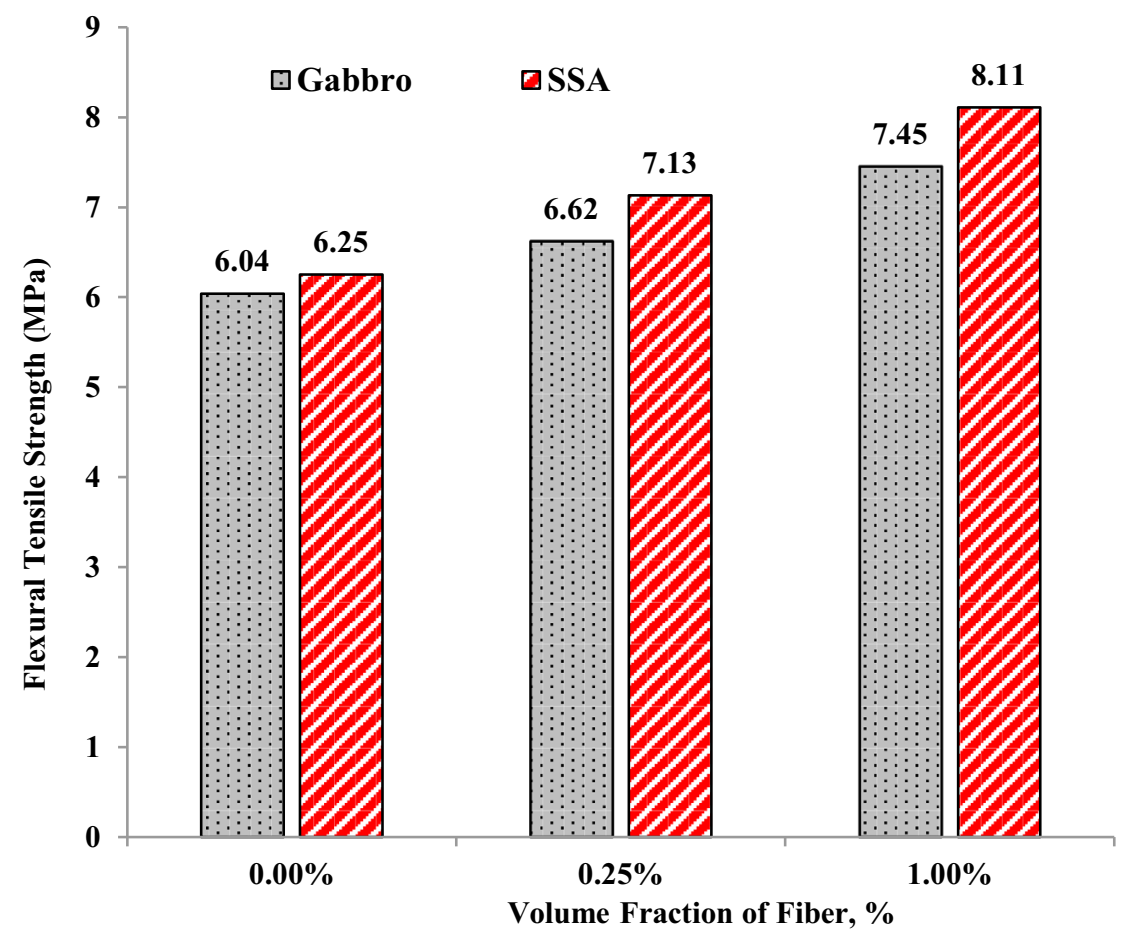

Fig. 4: Flexural testing results.

\section{Conclusions}

Preliminary test results on the use of steel slag aggregates and chopped basalt fibres in concrete mixes were presented. Compression tests on standard cylinders and flexural tests on standard prisms were conducted. The following conclusions are withdrawn from these tests:

- The compressive and flexural strengths of concrete cast using steel slag aggregate had better results than the concrete made normal Gabbro aggregate.

- The addition of chopped basalt fibre at volume fractions of $0.25 \%$ and $1 \%$ to the Gabbro concrete did not show a clear correlation between the two parameters. However, adding of chopped basalt fibre at volume fractions of $0.25 \%$ and $1 \%$ to the Gabbro resulted in an increase in the flexural strength were $9.6 \%$ and $23 \%$, respectively.

- The addition of chopped basalt fibre at volume fractions of $0.25 \%$ and $1 \%$ to the SSA concrete resulted in an increase in the compressive strength of $3.8 \%$ and $15.8 \%$, respectively. The corresponding gains in the flexural strength were $14.1 \%$ and $29.8 \%$, respectively.

- Both compressive strength and flexural tensile strength of concrete made with steel slag aggregate were higher than those made with natural gabbro aggregates. Test results clearly showed that steel slag aggregate can be used as sustainable and eco-friendly alternative materials in concrete structures. 
The authors show their gratitude to Qatar University for their financial support through the internal research grant QUUG-CENG-CAE-14/15-5. The authors are grateful to the Slag Aggregates Producer. W.L.L (SAP) for providing the SSA. In particular, special thanks are due to Mr. Devassy Baby who was very supportive of the research proposal.

\section{References}

1. Qatar Steel Sustainability Report (2013): http://www.qatarsteel.com.qa/Publications/ SitePages /sustainreport.aspx.

2. I. Netinger, D. Bjegovic, and G. Vrhovac (2011). "Utilisation of steel slag as an aggregate in concrete," Materials and Structures, 44, 1565-1575.

3. H. Qasrawi (2012), "Use of Relatively High Fe2O3 Steel Slag as Coarse Aggregate in Concrete," ACI Material Journal V. 109, 2012, pp. 471-478.

4. S. Tarawneh, E. Gharaibeh, \& F. Saraireh (2014). "Effect of using steel slag aggregate on mechanical properties of concrete," American Journal of Applied Sciences, 11(5), 700 .

5. R. Krishnasami, R. Malathy (2013) "Significance of Blast Furnace Slag as Coarse Aggregate in Self Compacting Concrete", Applied Mechanics and Materials Vols. 357360, 2013, pp. 829-833.

6. V. Devi, B. Gnanavel (2014). "Properties of Concrete Manufactured using Steel Slag," $12^{\text {th }}$ Global Congress on Manufacturing and Management, GCMM2014. Procedia Engineering 97, pp 95 - 104.

7. K. Holschemacher, T. Mueller, and Y. Ribakov (2010). "Effect of steel fibers on mechanical properties of high-strength concrete," Materials and Design, 31(5), 26042615.

8. Y. Mohammadi, R. Carkon-Azad, S.P. Singh, and S. Kaushik (2009). "Impact resistance of steel fibrous concrete containing fibers of mixed aspect ratio," Construction and Building Materials, 23(1), 183-189.

9. J. Katzer and J. Domski (2012). "Quality and mechanical properties of engineered steel fibers used as reinforcement for concrete," Construction and Building Materials, 34, 243-248.

10. S. Adhikari (2013). "Mechanical and structural characterization of mini-bar reinforced concrete beams," Ph. D. Dissertation, University of Akron, USA

11. S. Bajaj (2012). "Effect of corrosion on physical and mechanical properties of reinforced concrete," M. Sc. Thesis, University of Akron, USA. 